\title{
High-performance electrochromic devices based on poly[Ni(salen)]-type polymer films
}

Marta Nunes, ${ }^{a}$ Mariana Araújo, ${ }^{a}$ Joana Fonseca, ${ }^{b}$ Cosme Moura, ${ }^{c}$ Robert Hillman ${ }^{d}$ and Cristina Freire ${ }^{\mathrm{a}^{*}}$

${ }^{a}$ REQUIMTE/LAQV, Departamento de Química e Bioquímica, Faculdade de Ciências, Universidade do Porto, 4169-007 Porto, Portugal

${ }^{\mathrm{b}}$ CeNTI, Rua Fernando Mesquita, 2785, 4760-034 Vila Nova de Famalicão, Portugal

${ }^{c}$ CIQ, Departamento de Química e Bioquímica, Faculdade de Ciências, Universidade do Porto, 4169-007 Porto, Portugal

${ }^{d}$ Department of Chemistry, University of Leicester, Leicester LE1 7 RH, UK

*Corresponding author: Dr. Cristina Freire; e-mail: acfreire@fc.up.pt Tel.: +35122 04020590; Fax: +351220402695. 
Table S1: Peak potentials in CVs during $1^{\text {st }}$ and $5^{\text {th }}$ scans of films electrodeposition.

\begin{tabular}{ccccccccc}
\hline \multirow{2}{*}{ Films } & \multicolumn{8}{c}{$\boldsymbol{E} / \mathbf{V}(\mathbf{v s} \mathbf{A g} / \mathbf{A g C l})$} \\
\cline { 2 - 9 } & Scan & $\boldsymbol{E}_{\text {paI }}$ & $\boldsymbol{E}_{\text {paII }}$ & $\boldsymbol{E}_{\text {paIII }}$ & $\boldsymbol{E}_{\text {paIV }}$ & $\boldsymbol{E}_{\text {pcl' }}$ & $\boldsymbol{E}_{\text {pcII }}$ & $\boldsymbol{E}_{\text {pcIII }}$ \\
\hline \multirow{2}{*}{$\operatorname{poly}[1]$} & $1^{\text {st }}$ & - & - & 0.87 & 1.08 & 0.20 & - & 0.69 \\
\cline { 2 - 9 } & $5^{\text {th }}$ & 0.42 & - & 0.91 & 1.08 & 0.22 & - & 0.64 \\
\hline \multirow{2}{*}{$\boldsymbol{p o l y [ 2 ]}$} & $1^{\text {st }}$ & - & - & 0.99 & - & 0.50 & $0.64-$ & - \\
\cline { 2 - 9 } & $5^{\text {th }}$ & 0.59 & 0.68 & 0.99 & 1.17 & 0.45 & 0.58 & 0.87 \\
\hline
\end{tabular}


Table S2: Peak potentials in CVs during $1^{\text {st }}$ and $5^{\text {th }}$ scans of films redox switching.

\begin{tabular}{|c|c|c|c|c|c|c|}
\hline \multirow{2}{*}{ Films } & \multirow{2}{*}{$\begin{array}{c}\text { Supporting } \\
\text { Electrolyte } \\
\text { solution }\end{array}$} & \multicolumn{5}{|c|}{$E / \mathrm{V}(\mathrm{vs} \mathrm{Ag/AgCl})$} \\
\hline & & Scan & $E_{\mathrm{paI}}$ & $E_{\text {paII }}$ & $\boldsymbol{E}_{\mathrm{pcl}}$ & $E_{\mathrm{pcII}}$ \\
\hline \multirow{4}{*}{ poly[1] } & \multirow{2}{*}{$\mathrm{LiClO}_{4} / \mathrm{CH}_{3} \mathrm{CN}$} & $1^{\text {st }}$ & 0.42 & 1.16 & 0.18 & 0.58 \\
\hline & & $5^{\text {th }}$ & 0.42 & 0.94 & 0.17 & 0.56 \\
\hline & \multirow{2}{*}{$\mathrm{LiClO}_{4} / \mathrm{PC}$} & $1^{\text {st }}$ & 0.39 & 1.16 & 0.20 & 0.66 \\
\hline & & $5^{\text {th }}$ & 0.43 & 1.00 & 0.20 & 0.66 \\
\hline \multirow{4}{*}{ poly[2] } & \multirow{2}{*}{$\mathrm{LiClO}_{4} / \mathrm{CH}_{3} \mathrm{CN}$} & $1^{\text {st }}$ & 0.68 & 1.07 & 0.41 & 0.83 \\
\hline & & $5^{\text {th }}$ & 0.68 & 1.03 & 0.41 & 0.81 \\
\hline & \multirow{2}{*}{$\mathrm{LiClO}_{4} / \mathrm{PC}$} & $1^{\mathrm{st}}$ & 0.87 & 1.29 & 0.19 & 0.58 \\
\hline & & $5^{\text {th }}$ & 0.88 & 1.27 & 0.19 & 0.56 \\
\hline
\end{tabular}


Table S3: XPS surface atomic percentages and atomic ratios for reduced and oxidized poly[2] films in $\mathrm{LiClO}_{4} / \mathrm{PC} 0.1 \mathrm{~mol} \mathrm{dm}^{-3}$.

\begin{tabular}{cccccc|ccc}
\hline \multirow{2}{*}{ Films } & \multicolumn{5}{c|}{ Atomic \% } & \multicolumn{3}{c}{ Atomic Ratios } \\
\cline { 2 - 9 } & $\mathbf{N i}$ & $\mathbf{C}$ & $\mathbf{N}$ & $\mathbf{O}$ & $\mathbf{C l}$ & $\mathbf{N} / \mathbf{N i}$ & $\mathbf{O} / \mathbf{N i}$ & $\mathbf{C l} / \mathbf{N i}$ \\
\hline Reduced state & 2.55 & 76.69 & 6.13 & 12.26 & 0.81 & 2.40 & 4.81 & 0.32 \\
Oxidized state & 1.89 & 65.98 & 5.78 & 22.76 & 3.28 & 3.06 & 12.04 & 1.74 \\
\hline
\end{tabular}


Table S4: Switching times measured along the chronoamperometric studies for poly[1] and poly[2] in $\mathrm{LiClO}_{4} / \mathrm{CH}_{3} \mathrm{CN}_{\text {and }} \mathrm{LiClO}_{4} / \mathrm{PC}(\mathrm{Figures} 7$ and S9).

\begin{tabular}{|c|c|c|c|c|c|c|c|}
\hline \multirow[b]{2}{*}{ Films } & \multirow{2}{*}{$\begin{array}{c}\text { Supporting } \\
\text { Electrolyte } \\
\text { solution }\end{array}$} & \multicolumn{6}{|c|}{ Switching times / s } \\
\hline & & $\begin{array}{l}\text { Number } \\
\text { of cycles }\end{array}$ & yellow - green & green - yellow & $\begin{array}{l}\begin{array}{l}\text { Number } \\
\text { of cycles }\end{array} \\
\end{array}$ & green - russet & russet - green \\
\hline \multirow{9}{*}{ poly[1] } & \multirow{3}{*}{$\mathrm{LiClO}_{4} / \mathrm{CH}_{3} \mathrm{CN}$} & 0 & 9.3 & 8.4 & 0 & 6.9 & 25.0 \\
\hline & & 1000 & 11.3 & 6.4 & 100 & 11.7 & 24.2 \\
\hline & & 2000 & 24.0 & 7.6 & 200 & 29.8 & 17.8 \\
\hline & \multirow{6}{*}{$\mathrm{LiClO}_{4} / \mathrm{PC}$} & 0 & 20.6 & 15.4 & 0 & 10.5 & 36.02 \\
\hline & & 1000 & 16.5 & 16.6 & 100 & 9.9 & 30.37 \\
\hline & & 2000 & 16.6 & 17.2 & 200 & 11.8 & 29.9 \\
\hline & & 3000 & 17.5 & 16.7 & 300 & 14.9 & 30.2 \\
\hline & & 6000 & 17.4 & 13.2 & & & \\
\hline & & 9000 & 17.9 & 9.9 & & & \\
\hline \multirow{6}{*}{ poly[2] } & \multirow{2}{*}{$\mathrm{LiClO}_{4} / \mathrm{CH}_{3} \mathrm{CN}$} & 0 & 9.9 & 3.3 & 0 & 20.78 & 14.3 \\
\hline & & 200 & 10.8 & 3.7 & 100 & - & 11.3 \\
\hline & \multirow{4}{*}{$\mathrm{LiClO}_{4} / \mathrm{PC}$} & 0 & 38.8 & 12.1 & 0 & 23.9 & 30.5 \\
\hline & & 200 & 39.1 & 12.2 & 100 & 17.2 & 24.9 \\
\hline & & 400 & 39.5 & 12.0 & 200 & 19.9 & 24.7 \\
\hline & & 600 & 38.8 & 12.0 & 300 & 20.0 & 22.0 \\
\hline
\end{tabular}


(a)

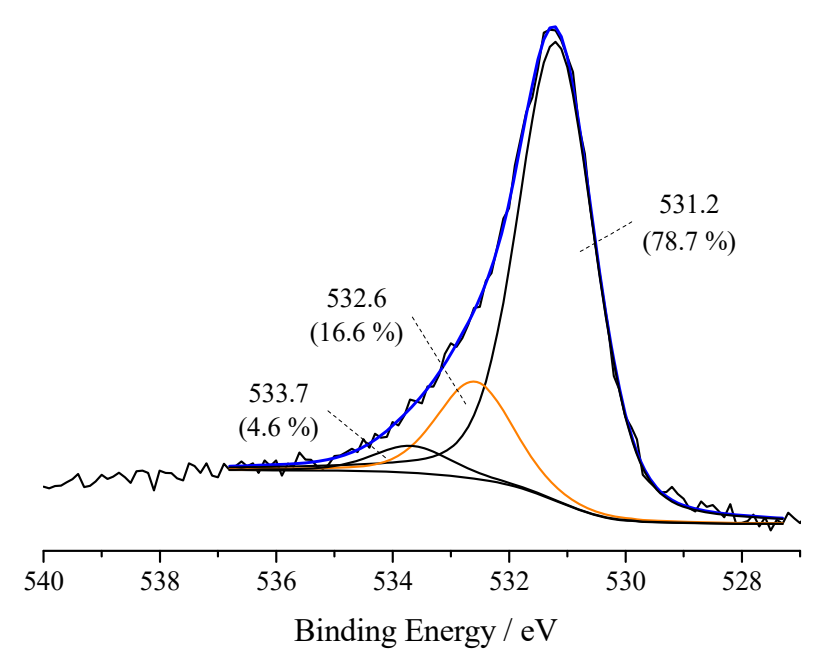

(b)

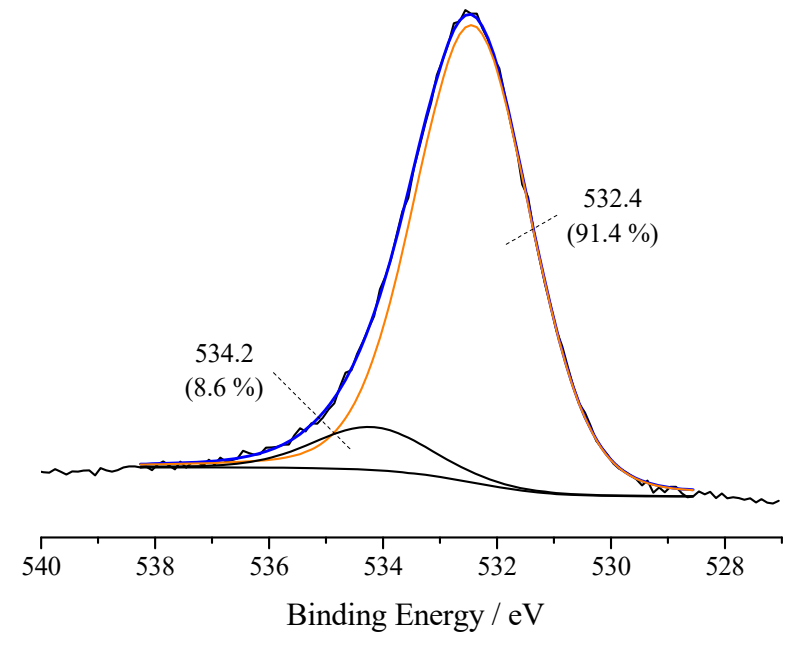

Figure S1. High-resolution XPS spectra in O 1s region of poly[1] film in (a) reduced and (b) oxidized states in $\mathrm{LiClO}_{4} / \mathrm{CH}_{3} \mathrm{CN}$, with respective deconvolutions; - peak assigned to $\mathrm{ClO}_{4}^{-}$. 
Panel A

Panel B

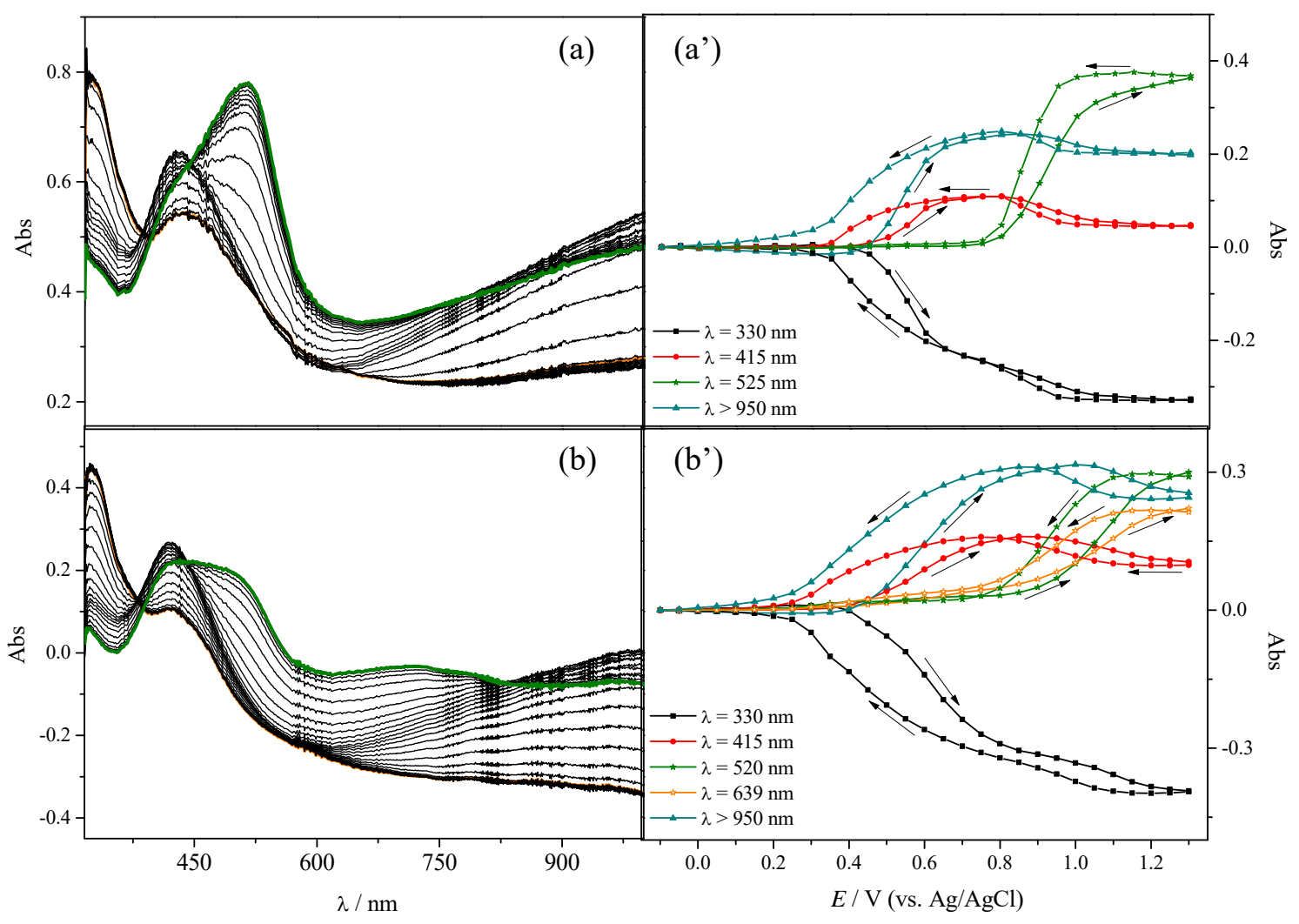

Figure S2. Panel A: Absolute UV-Visible spectra of poly[2] $\left(\Gamma=0.84 \mu \mathrm{mol} \mathrm{cm}{ }^{-2}\right)$ acquired during film oxidation in $0.1 \mathrm{~mol} \mathrm{dm}^{-3}$ (a) $\mathrm{LiClO}_{4} / \mathrm{CH}_{3} \mathrm{CN}$ and (b) $\mathrm{LiClO}_{4} / \mathrm{PC}$ (referenced to respective electrolytes; - spectra at $-0.1 \mathrm{~V},-$ spectra at $1.3 \mathrm{~V}$ ). Panel B: Abs vs. $E$ plots for electronic bands identified in absolute UV-Vis spectra, referenced to spectra at $-0.1 \mathrm{~V}$ (arrows indicate scan direction). 
Panel A

Panel B

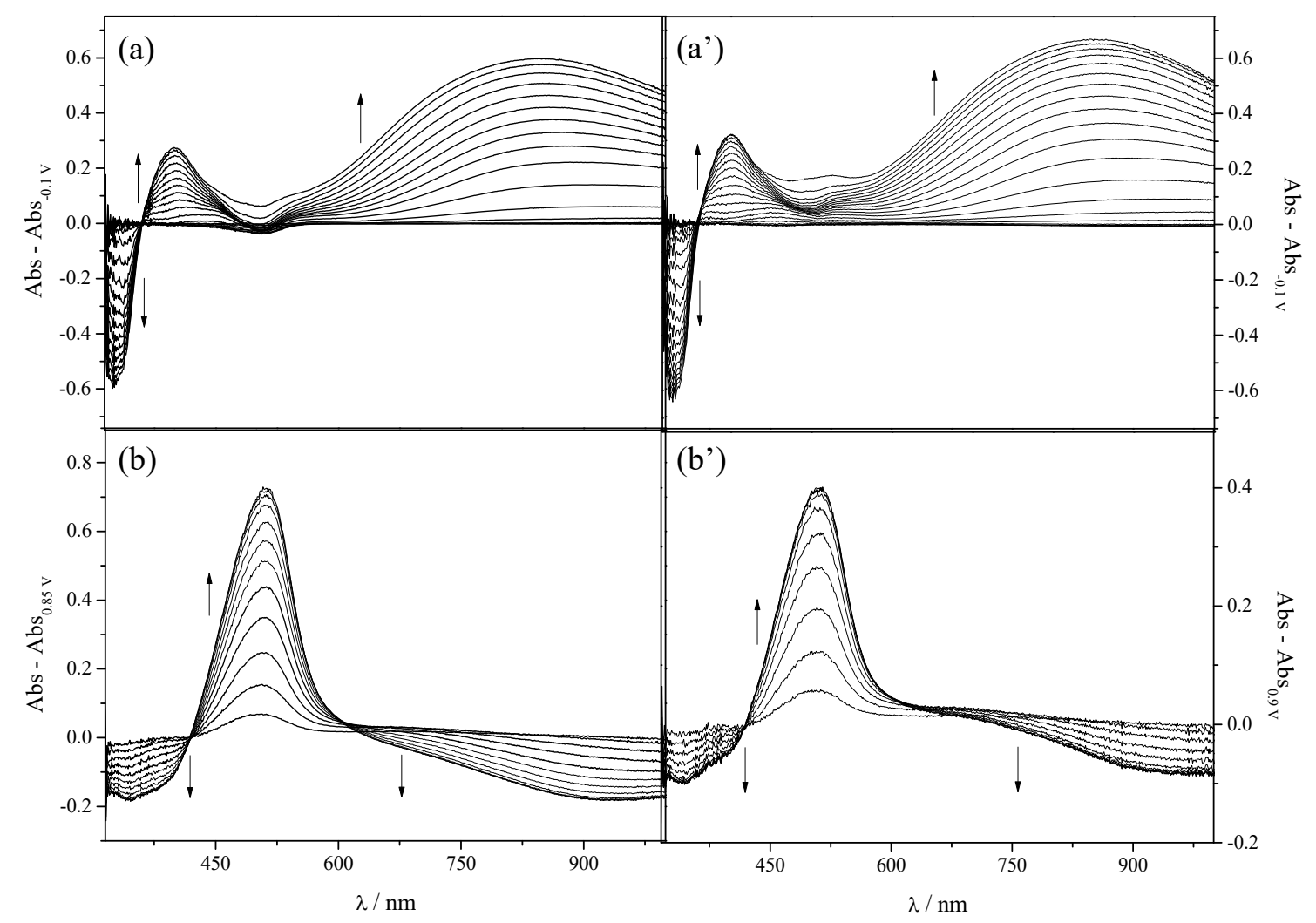

Figure S3. UV-Visible spectra of poly[1] $\left(\Gamma=0.16 \mu \mathrm{mol} \mathrm{cm} \mathrm{cm}^{-2}\right)$ acquired during the film oxidation in $\mathrm{LiClO}_{4} / \mathrm{CH}_{3} \mathrm{CN}$ (Panel A) and $\mathrm{LiClO}_{4} / \mathrm{PC}$ (Panel B) from (a) -0.1 to $0.85 \mathrm{~V}$ and referenced to the spectrum of neutral polymer, (b) 0.85 to $1.3 \mathrm{~V}$ and referenced to the spectrum of the polymer at $0.85 \mathrm{~V},\left(\mathrm{a}^{\prime}\right)-0.1$ to $0.9 \mathrm{~V}$ and referenced to the spectrum of neutral polymer and (b') 0.9 to $1.3 \mathrm{~V}$ and referenced to the spectrum of the polymer at $0.9 \mathrm{~V}$. 


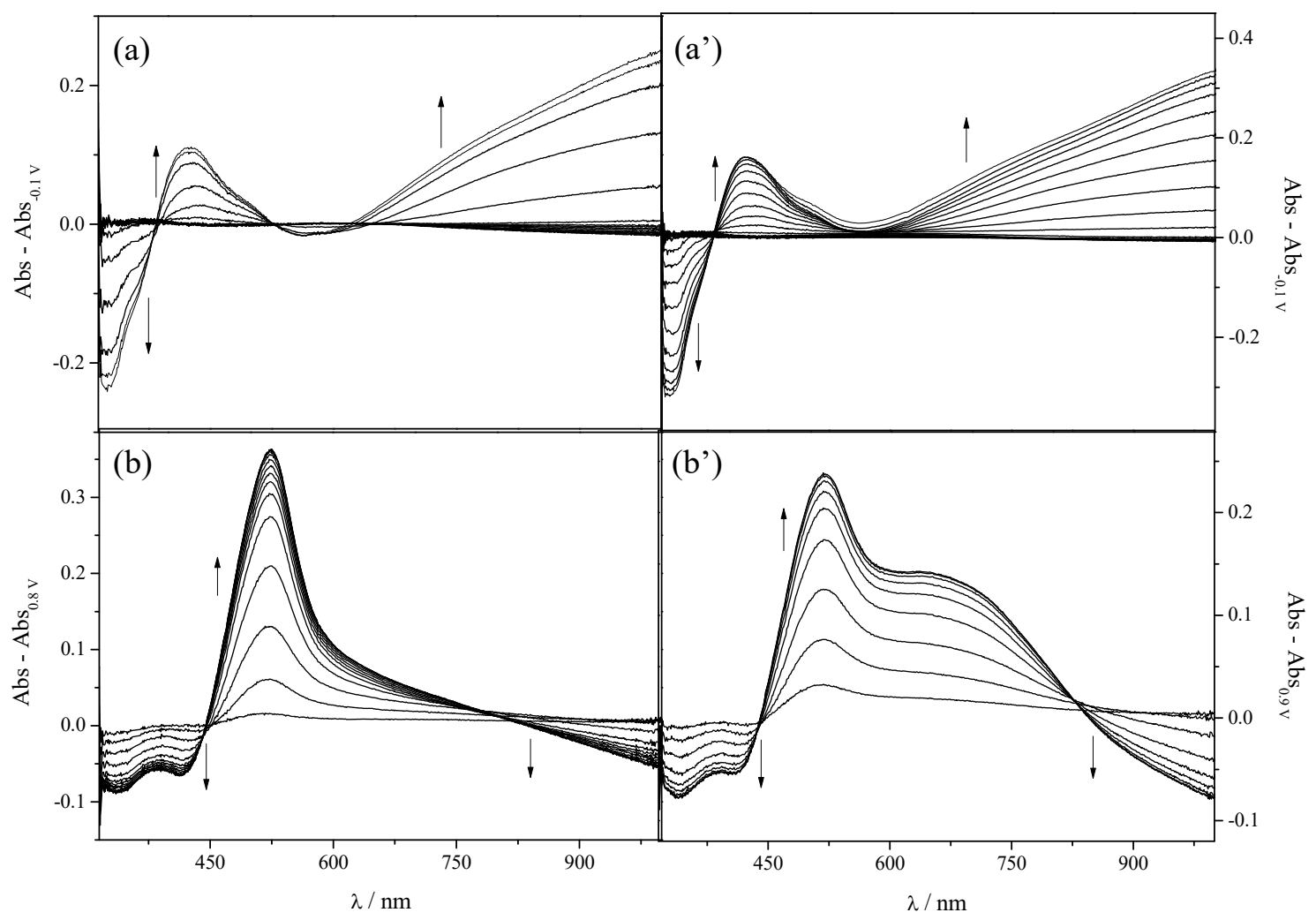

Figure S4. UV-Visible spectra of poly[2] $\left(\Gamma=0.84 \mu \mathrm{mol} \mathrm{cm} \mathrm{cm}^{-2}\right)$ acquired during the film oxidation in $\mathrm{LiClO}_{4} / \mathrm{CH}_{3} \mathrm{CN}$ (Panel A) and $\mathrm{LiClO}_{4} / \mathrm{PC}$ (Panel B) from (a) -0.1 to $0.8 \mathrm{~V}$ and referenced to the spectrum of neutral polymer, (b) 0.8 to $1.3 \mathrm{~V}$ and referenced to the spectrum of the polymer at $0.8 \mathrm{~V},\left(\mathrm{a}^{\prime}\right)-0.1$ to $0.9 \mathrm{~V}$ and referenced to the spectrum of neutral polymer and (b') 0.9 to $1.3 \mathrm{~V}$ and referenced to the spectrum of the polymer at $0.9 \mathrm{~V}$. 
Panel A

Panel B

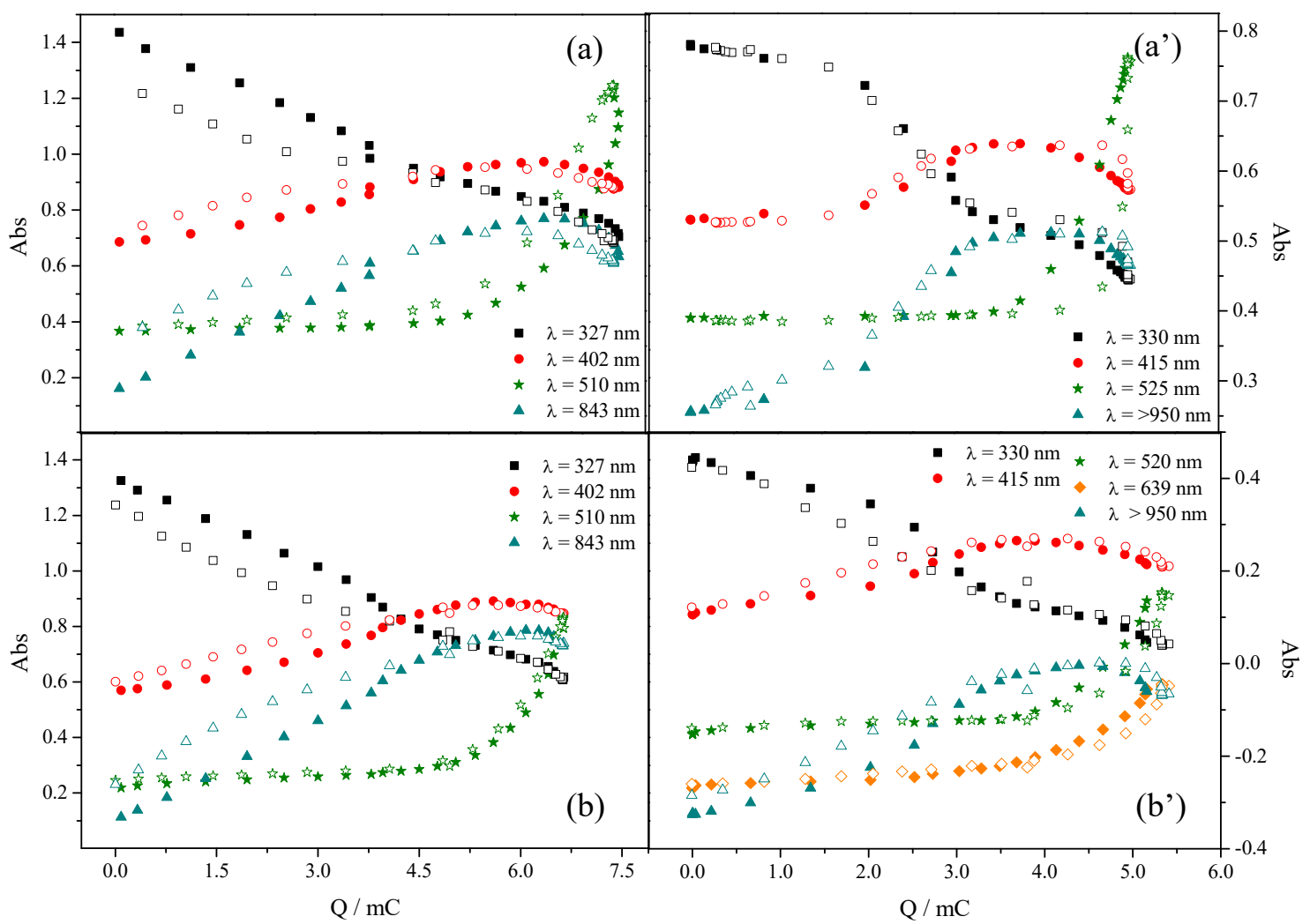

Figure S5. Plots of the $A b s$ vs. $Q$ for selected electronic bands for poly[1] (Panel A) and poly[2] (Panel B) in $\mathrm{LiClO}_{4} / \mathrm{CH}_{3} \mathrm{CN}$ (a and a') and $\mathrm{LiClO}_{4} / \mathrm{PC}$ (b and b'); filled forms correspond to anodic scan and open forms to cathodic scan. 

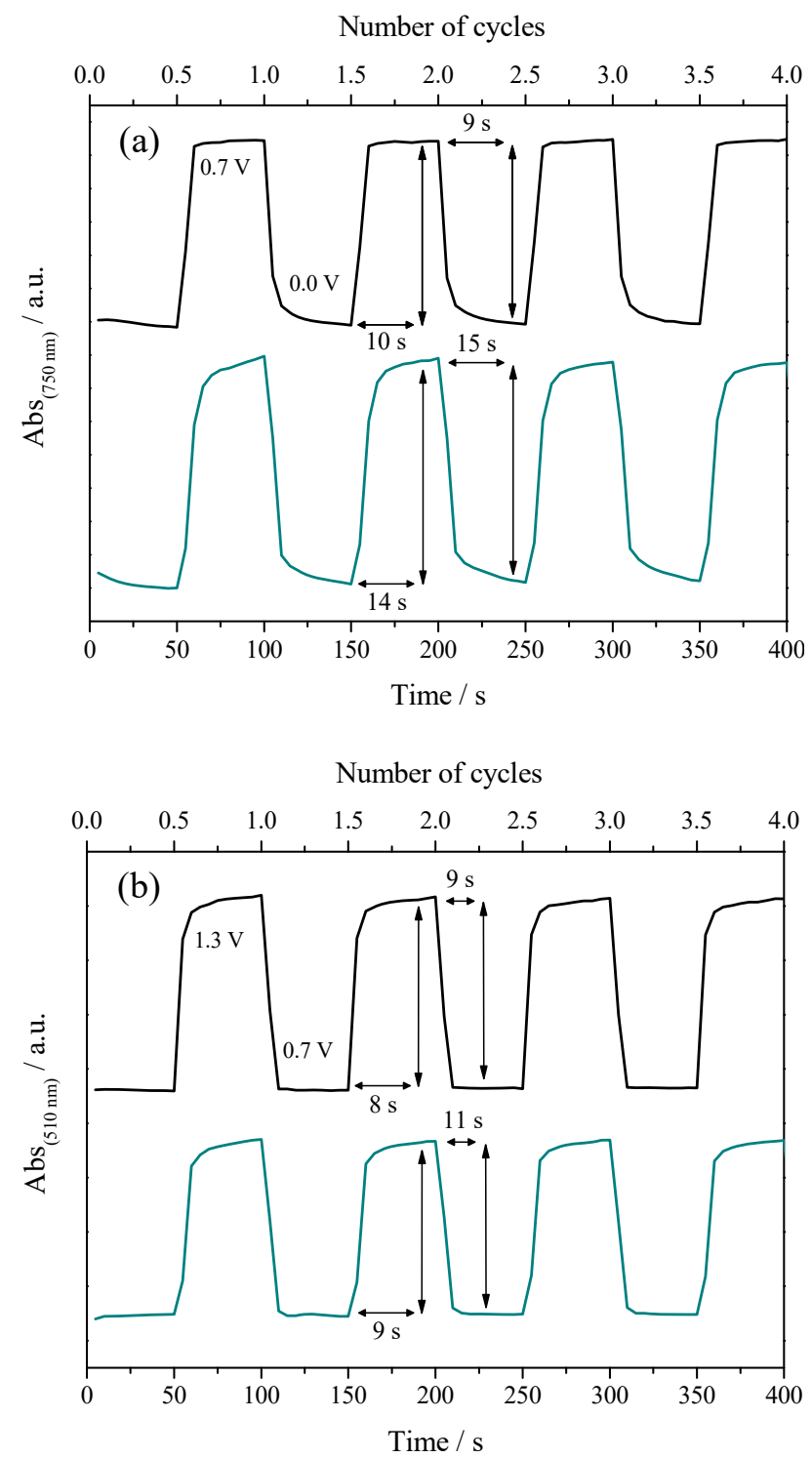

Figure S6. Chronoabsorptograms obtained for poly[2] films in $\mathrm{LiClO}_{4} / \mathrm{CH}_{3} \mathrm{CN}(-)$ and $\mathrm{LiClO}_{4} / \mathrm{PC}(-)$, for the colour transitions (a) yellow $\leftrightarrow$ green $(\lambda=750 \mathrm{~nm})$ and (b) green $\leftrightarrow \operatorname{russet}(\lambda=510 \mathrm{~nm})$, with indication of the estimated switching times. 
Panel A

Panel B

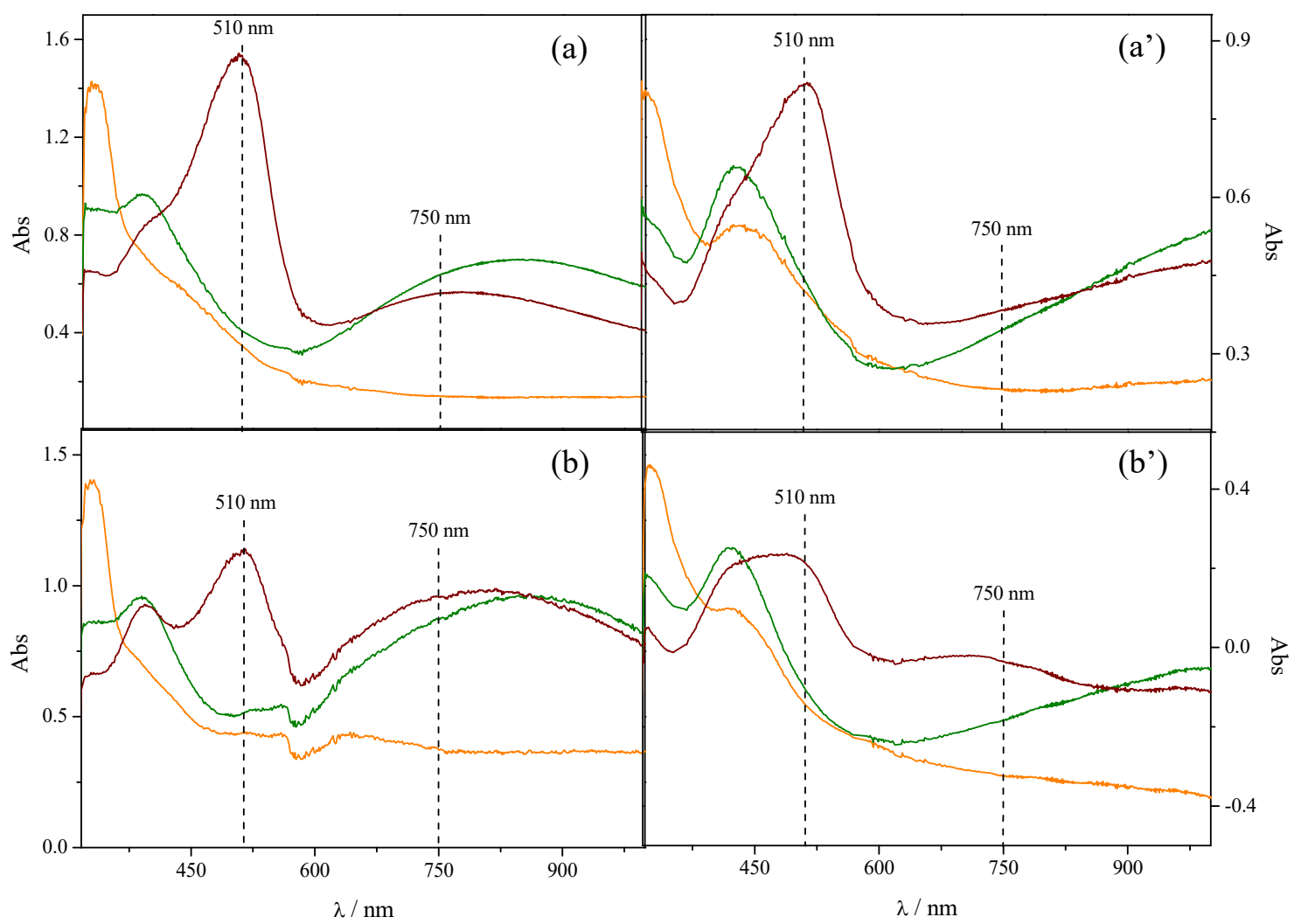

Figure S7. UV-Vis spectra of poly[1] (Panel A) and poly[2] (Panel B) films in $\mathrm{LiClO}_{4} / \mathrm{CH}_{3} \mathrm{CN}$ (a and a') and $\mathrm{LiClO}_{4} / \mathrm{PC}$ (b and b') in different oxidation states, corresponding to the colours yellow $(0.0 \mathrm{~V},-)$, green $(0.7 \mathrm{~V},-)$ and russet $(1.3 \mathrm{~V},-)$. The spectra were acquired after applying the indicated potential values during $50 \mathrm{~s}$. 

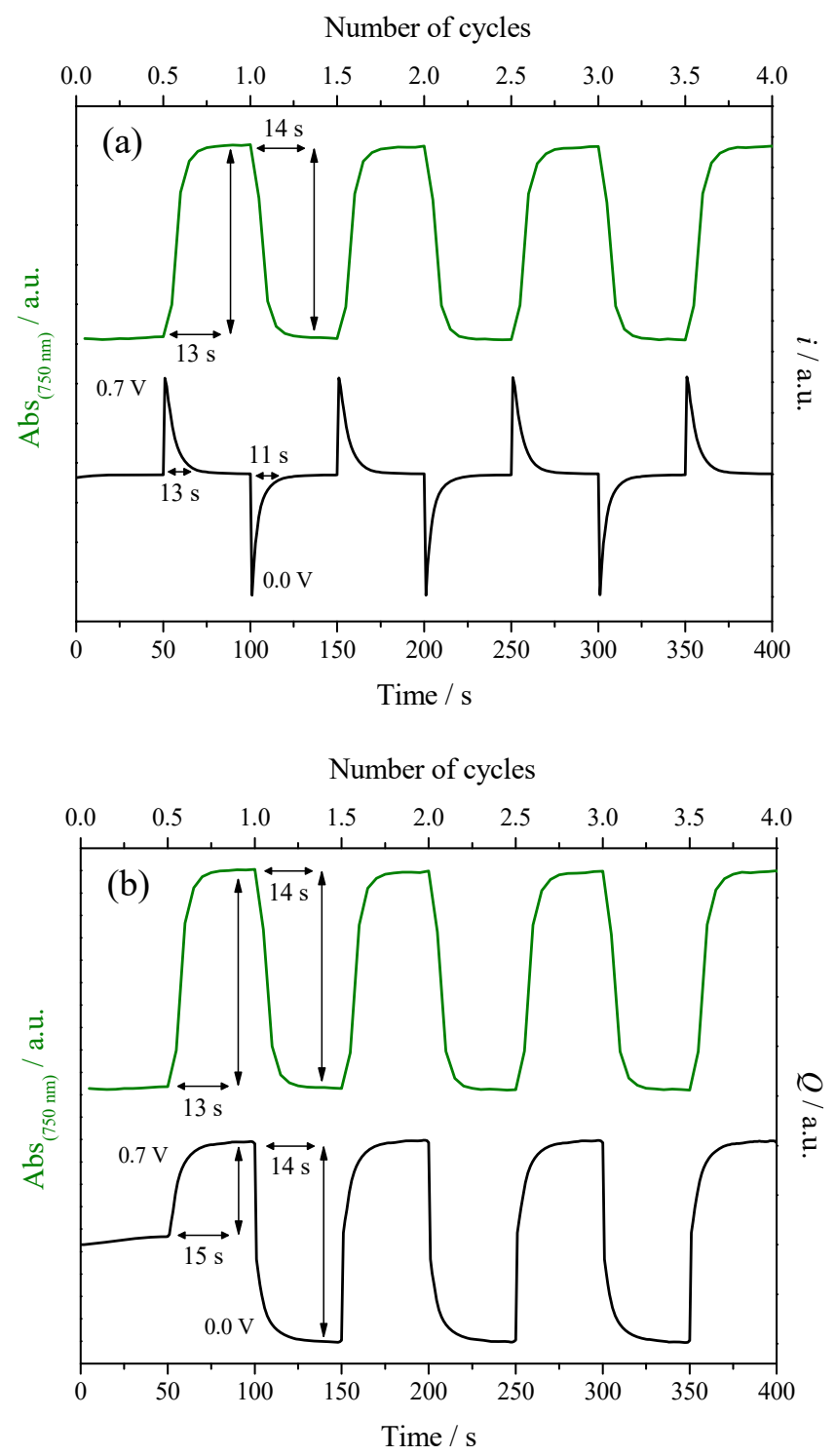

Figure S8. Chronoabsorptograms and (a) chronoamperograms or (b) chronocoulograms obtained in simultaneous for poly[1] films in $\mathrm{LiClO}_{4} / \mathrm{PC}$, considering the colour transition yellow $\leftrightarrow$ green $(\lambda=750 \mathrm{~nm})$; in chronoamperometric study were applied two potential pulses of $50 \mathrm{~s}$ by redox cycle, with potential alternating between 0.0 and $0.7 \mathrm{~V}$. 

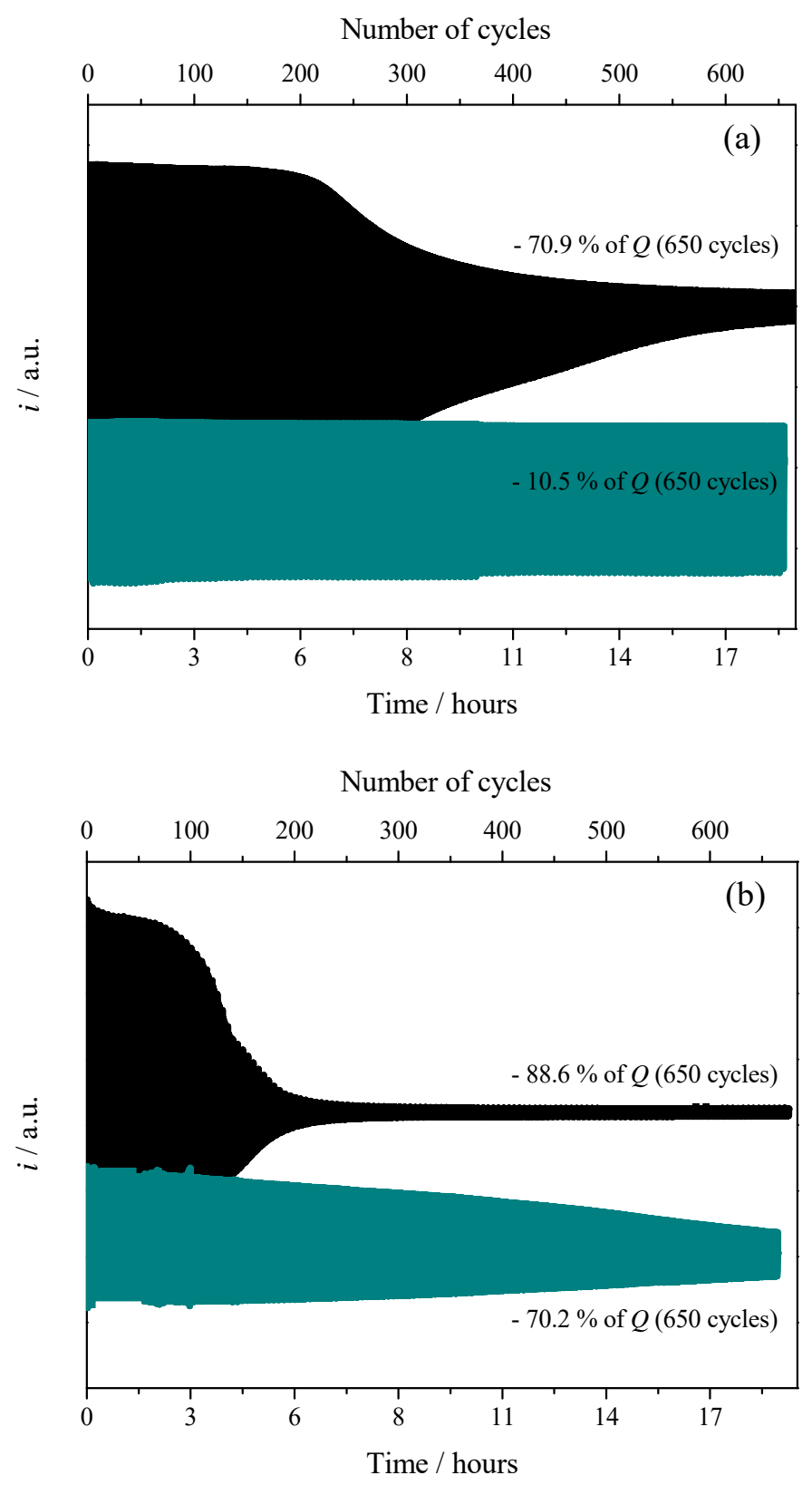

Figure S9. Chronoamperograms of poly[2] films in $\mathrm{LiClO}_{4} / \mathrm{CH}_{3} \mathrm{CN}(-)$ and $\mathrm{LiClO}_{4} / \mathrm{PC}$ (-) for the colour changes (a) yellow-green and (b) green-russet, applying two potential pulses of $50 \mathrm{~s}$ by redox cycle, with potential alternating between (a) $0.0-0.7 \mathrm{~V}$ and (b) $0.7-1.15 \mathrm{~V}$. 


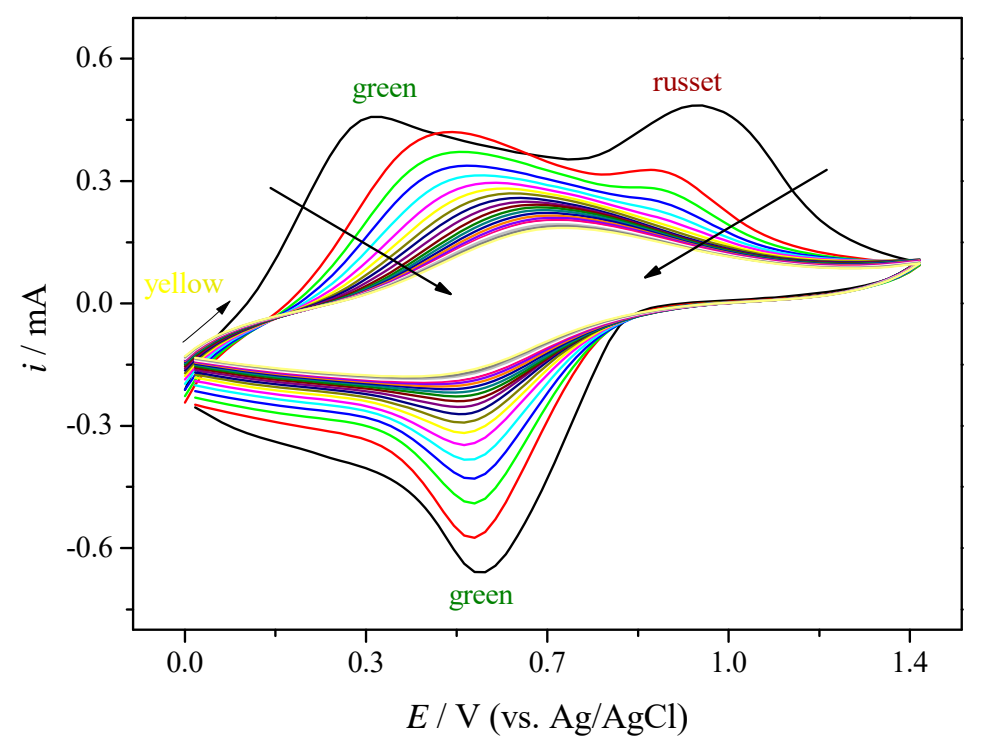

Figure S10. Voltammetric responses of poly[1] in $\mathrm{LiClO}_{4} / \mathrm{PC} 0.1 \mathrm{~mol} \mathrm{dm}^{-3}$, obtained at scan rate of $20 \mathrm{mV} \mathrm{s}^{-1}$, during 200 scans. 


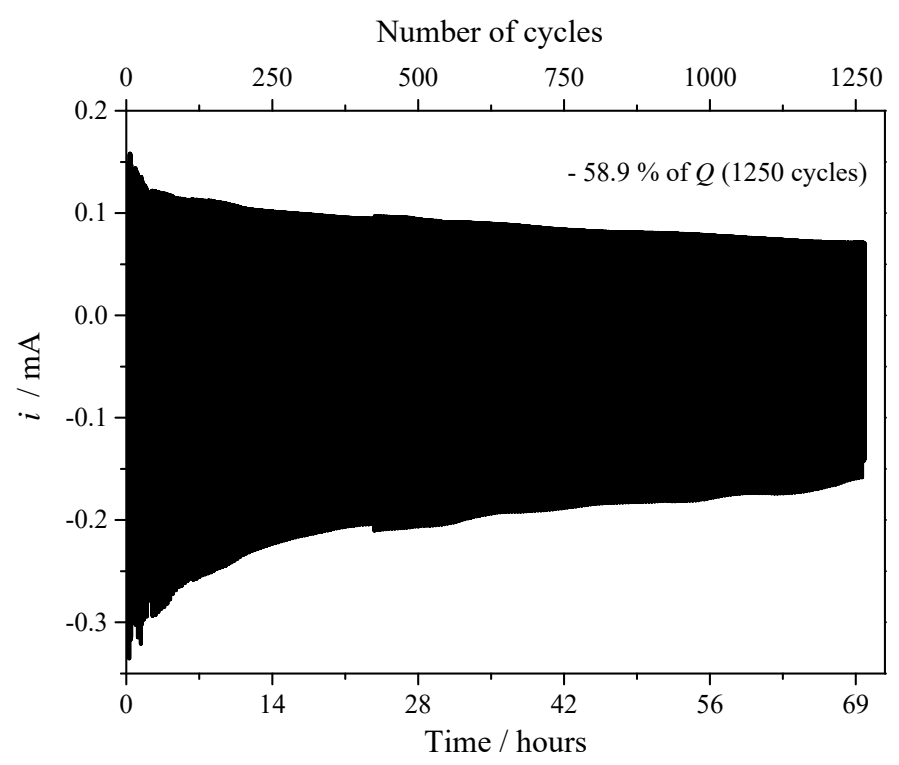

Figure S11. Chronoamperograms of the ECD of typology 2, applying two potential pulses of $100 \mathrm{~s}$ by redox cycle, with potential alternating between -1.1 (yellow) and -0.25 V (green). 